\title{
Fluid balance and cardiac function in septic shock as predictors of hospital mortality
}

\author{
Scott T Micek', Colleen McEvoy², Matthew McKenzie', Nicholas Hampton ${ }^{3}$, Joshua A Doherty ${ }^{4}$ and Marin H Kollef2
}

\begin{abstract}
Introduction: Septic shock is a major cause of morbidity and mortality throughout the world. Unfortunately, the optimal fluid management of septic shock is unknown and currently is empirical.

Methods: A retrospective analysis was performed at Barnes-Jewish Hospital (St. Louis, Missouri). Consecutive patients $(n=325)$ hospitalized with septic shock who had echocardiographic examinations performed within 24 hours of shock onset were enrolled.

Results: A total of 163 (50.2\%) patients with septic shock died during hospitalization. Non-survivors had a significantly larger positive net fluid balance within the 24 hour window of septic shock onset (median (IQR): $4,374 \mathrm{ml}(1,637 \mathrm{ml}, 7,260 \mathrm{ml})$ vs. 2,959 ml $(1,639.5 \mathrm{ml}, 4,769.5 \mathrm{ml}), P=0.004)$. The greatest quartile of positive net fluid balance at 24 hours and eight days post-shock onset respectively were found to predict hospital mortality, and the greatest quartile of positive net fluid balance at eight days post-shock onset was an independent predictor of hospital mortality (adjusted odds ratio (AOR), 1.66; $95 \% \mathrm{Cl}, 1.39$ to $1.98 ; P=0.004$ ). Survivors were significantly more likely to have mild left ventricular dysfunction as evaluated by bedside echocardiography and non-survivors had slightly elevated left ventricular ejection fraction, which was also found to be an independent predictor of outcome.
\end{abstract}

Conclusions: Our data confirms the importance of fluid balance and cardiac function as outcome predictors in patients with septic shock. A clinical trial to determine the optimal administration of intravenous fluids to patients with septic shock is needed.

\section{Introduction}

Septic shock is a common disorder faced by clinicians working in the ICU setting. Intravenous fluids, along with appropriate antibiotic therapy, source control, vasopressors, inotropes and ventilator support are key elements of the management of septic shock [1]. The administration of intravenous fluids is largely empiric, although goal-directed approaches have been evaluated in an attempt to optimize fluid resuscitation of septic shock [2-4]. It is now recognized that excessive fluid administration in septic shock may contribute to acute lung injury (ALI), abdominal compartment syndrome, coagulopathy and cerebral edema [5-8]. We previously demonstrated that both early and late fluid management

\footnotetext{
*Correspondence: mkollef@dom.wustl.edu

${ }^{2}$ Division of Pulmonary and Critical Care Medicine, Washington University School of Medicine, 660 South Euclid Avenue, Campus Box 8052, St. Louis, MO 63110, USA

Full list of author information is available at the end of the article
}

of septic shock complicated by ALI may influence patient outcomes [9]. Other investigators have recently demonstrated that positive net fluid balance is associated with increased risk of mortality in septic shock $[10,11]$. Moreover, the presence of cardiac dysfunction resulting from septic shock may also be an important predictor of outcome, although not all studies are in agreement on this point [12-14]. Therefore, we set out to perform a study with two main goals. The first study goal was to determine the relationship between net fluid balance and hospital mortality in a well described cohort of patients with septic shock. The second study goal was to assess whether the identification of newly recognized cardiac dysfunction influenced cumulative fluid balance or hospital mortality in patients with septic shock.

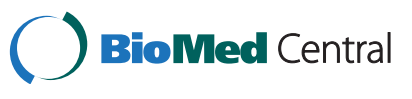

(c) 2013 Micek et al.; licensee BioMed Central Ltd. This is an open access article distributed under the terms of the Creative Commons Attribution License (http://creativecommons.org/licenses/by/2.0), which permits unrestricted use, distribution, and reproduction in any medium, provided the original work is properly cited. 


\section{Materials and methods Study location and patients}

The study was conducted at Barnes-Jewish Hospital/ Washington University Medical Center (1,300 beds) in St. Louis, MO and approved by the Institutional Review Board of Washington University. Patients with septic shock having a transthoracic echocardiographic examination performed within 24 hours of the onset of septic shock between 1 January 2009 and 31 December 2011 were eligible for this investigation. Patients were excluded if they had known pre-existing non-sepsis related cardiovascular compromise as defined by acute myocardial infarction, cardiogenic shock or a history of congestive heart failure with a left ventricle ejection fraction (LVEF) less than 40\%; had a requirement for extracorporeal membrane oxygenation or a ventricular assist device; or developed septic shock at an outside hospital requiring vasopressor and fluid management prior to transfer.

\section{Study design}

A retrospective cohort study was performed with the primary outcome being hospital mortality. Secondary outcomes included ICU and hospital length of stay, total quantity of intravenous and enteral fluids administered and the prescription of appropriate initial antimicrobial treatment. For the purposes of determining compliance with early, goal-directed treatment guidelines and the timing of antibiotic administration, the time of septic shock onset was defined as the time that a vasopressor agent was first administered. All pertinent data were then collected relative to this time.

\section{Data collection}

Patients with septic shock were identified electronically by ICD 9 codes for acute organ dysfunction and acute infection and by an active order for a vasopressor through the pharmacy database at Barnes-Jewish Hospital [15]. Data were collected retrospectively from automated patient medical records and pharmacy databases at Barnes-Jewish Hospital (MM, STM). Pertinent demographic, laboratory and clinical data were gathered including: age, gender, race, patient location at the time of septic shock onset, severity of illness based on the Acute Physiology and Chronic Health Evaluation (APACHE) II score [16], co-morbidities, Charlson co-morbidity score, site of the infection and positive cultures with sensitivities. Patient-specific factors starting at the time of septic shock onset were also collected including vital signs, central venous pressure (CVP), central venous hemoglobin oxygen saturation $\left(\mathrm{S}_{\mathrm{CV}} \mathrm{O}_{2}\right)$ and laboratory data. Information regarding the management of septic shock was recorded including adequate initial fluid resuscitation (AIFR), appropriate antimicrobial administration, corticosteroid administration and daily fluid balance.

\section{Definitions}

Septic shock was defined as noted above by an ICD9 code for acute organ dysfunction (for example, acute renal failure, respiratory failure) in the presence of an acute infection and by an active order for a vasopressor that was administered for greater than 12 hours [15]. Onset of septic shock was defined as the time of vasopressor initiation. AIFR was defined as the administration of an initial fluid bolus $\geq 20 \mathrm{~mL} / \mathrm{kg}$ and achievement of a CVP $\geq 8 \mathrm{~mm} \mathrm{Hg}$ within eight hours after the onset of therapy with vasopressors. This was dictated by the hospital's sepsis protocol and order set applied to all patients, as was the early use of vasopressors in patients with septic shock $[17,18]$. Appropriate empiric antimicrobial therapy was defined as antimicrobials given within 24 hours of the onset of septic shock that were active against the pathogen associated with infection based on susceptibility testing [19].

\section{Echocardiographic evaluation and definitions of myocardial dysfunction}

Transthoracic echocardiography was performed in the ICU by certified echosonographers with a commercial instrument (Vivid I, GE Medical Systems, Milwaukee, WI, USA). All echocardiograms were interpreted by boardcertified cardiologists from Washington University School of Medicine Cardiovascular Division. A comprehensive Mmode, two-dimensional and Doppler echocardiographic study was performed from the parasternal long- and shortaxis views; apical four-chamber, two-chamber and long-axis views; and subcostal views.

LV end-diastolic volume, LV end-systolic volume, and LVEF using the modified Simpson method were assessed as recommended by the American Society of Echocardiography [20]. Measurements were taken during three cardiac cycles and then averaged. Systolic dysfunction was defined as mild (LVEF, $45 \%$ to $54 \%$ ), moderate (LVEF, 30\% to $44 \%$ ), and severe (LVEF, $<30 \%$ ). Whenever suboptimal endomyocardial border definition was encountered for volumetric assessment, M-mode imaging and expert visual estimation by the interpreting cardiologist determined the final LVEF. Diastolic function evaluation was performed in accordance with the American Society of Echocardiography guidelines and graded as absent or present with or without evidence of increased filling pressures [21]. A multimodal approach was used to evaluate for right ventricle (RV) dysfunction, which was graded as mild, moderate or severe. Lateral tricuspid annulus peak systolic velocity measured by tissue Doppler imaging (TDI) was used in association with the relative RV-to-LV size, motion of the RV wall, and expert evaluation 
by the interpreting cardiologist [22]. RV peak systolic velocity less than $15 \mathrm{~cm} / \mathrm{s}$ was considered diminished lateral RV systolic motion consistent with RV dysfunction.

\section{Statistical analysis}

The primary data analysis compared hospital survivors to hospital non-survivors. Continuous data were reported as the mean $\pm S D$ for parametric data and the median with interquartile ranges for non-parametric data. The Student's $t$-test was used when comparing parametric data and the Mann-Whitney $U$ test was employed to analyze non-parametric data. Categorical data were expressed as frequency distributions, and the Chi-squared test was used to determine if differences existed between groups. After univariate analysis, stepwise multivariable logistic regression was undertaken to determine independent risk factors for hospital mortality. Risk factors significant at the 0.10 level in the univariate analysis were included in the models, with the exception of cardiac function parameters which were included regardless of the univariate $P$-values. All tests were two-tailed, and a $P$-value $<0.05$ was determined to represent statistical significance. Cox regression analysis stratified according to fluid balance quartiles was used to adjust for the confounding effects of age, severity of illness and use of vasopressin. Analyses were performed using SPSS, version 11.0 for Windows (SPSS, Inc., Chicago, IL, USA).

In addition, the influence of fluid balance on hospital mortality was further estimated using propensity scores. In our study, propensity scores were estimated by fitting a logistic regression. The covariates included in the propensity score model were those with a potential impact on outcome: age, body mass index, Charlson comorbidity score, gender, APACHE II, mechanical ventilation, chronic obstructive pulmonary disease, coronary artery disease, chronic renal disease, cirrhosis, underlying malignancy, diabetes, LV dysfunction, RV dysfunction, diastolic dysfunction and LVEF. Propensity score quintiles were derived, and boxplots of the estimated propensity scores for the highest and lowest quartiles of fluid balance within each quintile of the propensity scores were plotted to assess the validity of the analysis. Finally, we fitted a logistic model for hospital mortality including as covariates the propensity score and fluid balance.

\section{Results}

Patients

A total of 325 consecutive patients were included in the study, of whom 162 (49.8\%) survived and 163 (50.2\%) died during hospitalization. Hospital non-survivors were statistically older, had greater severity of illness measured by APACHE II scores, and were more likely to have required mechanical ventilation (Table 1).

\section{Fluid balance and process of care variables}

Table 2 outlines the process of care variables. Nonsurvivors had a larger net fluid balance within the 24-hour window of septic shock onset (Table 2). Non-survivors also had a larger net fluid balance within the eight-day window of septic shock onset (median (interquartile range (IQR)): $7,742 \mathrm{ml}(2,914 \mathrm{ml}, 15,992 \mathrm{ml})$ vs. $3,286.5 \mathrm{ml}$ $(1,508.5 \mathrm{ml}, 7,467 \mathrm{ml}), P<0.001)$. There was no difference in AIFR or CVP and $\mathrm{S}_{\mathrm{CV}} \mathrm{O}_{2}$ measurements or attainment of a CVP $\geq 8 \mathrm{mmHg}$ and $\mathrm{S}_{\mathrm{CV}} \mathrm{O}_{2} \geq 70 \%$. Figure 1 shows that significantly greater daily net fluid balance occurred in non-survivors for days 1 through 6 following septic shock onset.

Survival curves adjusted for age, APACHE II scores and vasopressin use are shown in Figure 2. Both at 24 hours and at Day 8, one's fluid balance quartile predicted survival. At 24 hours, compared with quartiles 1 and 2, the risk of survival in Quartile 4 was significantly lower $(P=0.001$ and $P=0.034$, respectively, by log-rank test) ( $P=0.162$ for quartile 4 compared to Quartile 3 ) (Figure 2, Top). At eight days, compared with quartiles 1 and 2, the risk of survival in Quartile 4 was significantly lower $(P<0.001$ and $P=0.008$, respectively, by log-rank test) $(P=0.60$ for Quartile 4 compared to Quartile 3$)$ (Figure 2, Bottom).

\section{Table 1 Baseline characteristics}

\begin{tabular}{|c|c|c|c|}
\hline Variable & $\begin{array}{l}\text { Survivors } \\
N=162\end{array}$ & $\begin{array}{l}\text { Nonsurvivors } \\
N=163\end{array}$ & $P$-value \\
\hline Age, yrs: & $58.5 \pm 14.6$ & $63.0 \pm 14.0$ & 0.005 \\
\hline Male, n(\%): & $75(46.3)$ & $73(44.8)$ & 0.784 \\
\hline \multicolumn{4}{|l|}{ Race, $n(\%):$} \\
\hline Caucasian & $107(66.0)$ & $121(74.2)$ & 0.107 \\
\hline African-American & $50(30.9)$ & $41(25.2)$ & 0.252 \\
\hline Other & $5(3.1)$ & $1(0.6)$ & 0.121 \\
\hline Body mass index $\geq 40, n(\%)$ : & $30.6 \pm 10.9$ & $29.7 \pm 9.7$ & 0.552 \\
\hline Charlson comorbidity score: & $3.4 \pm 3.3$ & $4.4 \pm 3.2$ & 0.111 \\
\hline \multicolumn{4}{|l|}{ Coexisting conditions, $n(\%)$ : } \\
\hline Coronary artery disease & $18(11.2)$ & $9(5.5)$ & 0.072 \\
\hline $\begin{array}{l}\text { Chronic obstructive } \\
\text { lung disease }\end{array}$ & $42(26.1)$ & $39(23.9)$ & 0.701 \\
\hline Cirrhosis & $29(17.9)$ & $37(22.7)$ & 0.335 \\
\hline Chronic kidney disease & $29(17.9)$ & $22(13.5)$ & 0.290 \\
\hline Diabetes & $43(26.5)$ & $39(23.9)$ & 0.611 \\
\hline Active malignancy & $21(13.0)$ & $28(17.2)$ & 0.353 \\
\hline APACHE II: & $21.7 \pm 6.3$ & $25.1 \pm 6.7$ & $<0.001$ \\
\hline Mechanical ventilation, $\mathrm{n}(\%)$ : & $114(70.4)$ & $140(85.9)$ & 0.001 \\
\hline Bloodstream infection, n(\%): & $29(17.9)$ & $34(20.9)$ & 0.575 \\
\hline
\end{tabular}

Values are expressed as mean \pm SD. APACHE, Acute Physiology and Chronic Health Evaluation; HIV, human immunodeficiency. 
Table 2 Process of care variables

\begin{tabular}{|c|c|c|c|}
\hline Variable & $\begin{array}{l}\text { Survivors } \\
\mathrm{N}=162\end{array}$ & $\begin{array}{l}\text { Nonsurvivors } \\
N=163\end{array}$ & $P$-value \\
\hline \multirow{2}{*}{$\begin{array}{l}\text { Fluid balance }(\mathrm{ml}) \text {, } \\
\text { within } 24 \text { hours of } \\
\text { septic shock onset }\end{array}$} & 2,959 & 4,374 & \multirow[t]{2}{*}{0.004} \\
\hline & $(1,639.5,4,769.5)$ & $(1,637,7,260)$ & \\
\hline \multirow{2}{*}{$\begin{array}{l}\text { Fluid balance }(\mathrm{ml} / \mathrm{kg}) \text {, } \\
\text { within } 24 \text { hours of septic } \\
\text { shock onset }\end{array}$} & 37.5 & 53.3 & \multirow[t]{2}{*}{0.022} \\
\hline & $(20.8,62.2)$ & $(19.8,91.7)$ & \\
\hline $\begin{array}{l}\text { Adequate initial fluid } \\
\text { resuscitation, } n(\%):^{*}\end{array}$ & $103(63.6)$ & $109(66.9)$ & 0.533 \\
\hline CVP measured, $\mathrm{n}(\%):^{*}$ & $146(90.1)$ & $147(90.2)$ & 0.985 \\
\hline CVP $\geq 8 \mathrm{~mm} \mathrm{Hg}, \mathrm{n}(\%): *$ & $138(94.5)$ & $143(97.3)$ & 0.256 \\
\hline $\mathrm{S}_{\mathrm{CVO}_{2}}$ measured, $\mathrm{n}(\%): *$ & $69(42.6)$ & $60(36.8)$ & 0.287 \\
\hline $\mathrm{S}_{\mathrm{CV}} \mathrm{O}_{2} \geq 70 \%, \mathrm{n}(\%): *$ & $62(89.9)$ & $50(83.3)$ & 0.275 \\
\hline PRBC administered, $\mathrm{n}(\%):^{*}$ & $21(13.0)$ & $31(19.0)$ & 0.137 \\
\hline \multicolumn{4}{|l|}{$\begin{array}{l}\text { Vasopressor and inotrope } \\
\text { usage, } \mathrm{n}(\%) \text { : }\end{array}$} \\
\hline Norepinephrine & $162(100.0)$ & $163(100.0)$ & 1.000 \\
\hline Dopamine & $12(7.4)$ & $16(9.8)$ & 0.439 \\
\hline Vasopressin & $9(5.6)$ & $34(20.9)$ & $<0.001$ \\
\hline Epinephrine & $9(5.6)$ & $24(14.7)$ & 0.006 \\
\hline Dobutamine & $34(21.0)$ & $50(30.7)$ & 0.046 \\
\hline $\begin{array}{l}\text { Requiring vasopressor } \\
\text { support at Day } 8 \text { post } \\
\text { septic shock onset, } n(\%) \text { : }\end{array}$ & $9(5.6)$ & $21(12.9)$ & 0.002 \\
\hline \multicolumn{4}{|l|}{$\begin{array}{l}\text { Left ventricular } \\
\text { dysfunction, n(\%): }\end{array}$} \\
\hline Mild & $22(13.6)$ & $10(6.1)$ & 0.024 \\
\hline Moderate & $15(9.3)$ & $15(9.2)$ & 0.986 \\
\hline Severe & $8(4.9)$ & $7(4.3)$ & 0.782 \\
\hline \multirow{2}{*}{$\begin{array}{l}\text { Left ventricle ejection } \\
\text { fraction, } n(\%) \text { : }\end{array}$} & $55(49,60)$ & $55(55,70)$ & \multirow[t]{2}{*}{0.038} \\
\hline & $(53.6 \pm 12.3)$ & $(56.5 \pm 11.8)$ & \\
\hline \multicolumn{4}{|l|}{$\begin{array}{l}\text { Right ventricular } \\
\text { dysfunction, } n(\%) \text { : }\end{array}$} \\
\hline Mild & $27(16.7)$ & $31(19.0)$ & 0.580 \\
\hline Moderate & $6(3.7)$ & $13(8.0)$ & 0.101 \\
\hline Severe & $1(0.6)$ & $1(0.6)$ & 1.000 \\
\hline Diastolic dysfunction & $56(34.6)$ & $45(27.6)$ & 0.175 \\
\hline $\begin{array}{l}\text { Appropriate initial antibiotic } \\
\text { therapy, } \mathrm{n}(\%) \text { : }\end{array}$ & $136(84.0)$ & $125(76.7)$ & 0.364 \\
\hline Corticosteroids, n(\%): & $51(31.5)$ & $83(50.9)$ & $<0.001$ \\
\hline
\end{tabular}

Values are expressed as median with inter-quartile range. CVP, central venous pressure; PRBC, packed red blood cell; $\mathrm{S}_{\mathrm{CV}} \mathrm{O}_{2}$, central venous hemoglobin oxygen saturation.

*Within 24 hours of the onset of septic shock.

All patients received norepinephrine (Table 2). Nonsurvivors were statistically more likely to also receive vasopressin, epinephrine and dobutamine compared to survivors. The median (IQR) duration of vasopressor use was significantly longer among non-survivors compared to survivors (three days (one day, five days) versus two days (one day, four days); $P=0.006$ ). Net fluid balance was significantly greater in patients receiving norepinephrine plus dobutamine, dopamine, epinephrine or vasopressin compared to norepinephrine alone (median (IQR): $4,194 \mathrm{ml}(1,650.5 \mathrm{ml}, 7,296 \mathrm{ml})$ vs. $3,147 \mathrm{ml}$ $(1,560.5 \mathrm{ml}, 5,385.5 \mathrm{ml}), P=0.029)$. There was also a modest correlation between CVP measured within 24 hours of shock onset and net fluid balance at 24 hours $(P=0.033)$.

Cardiac function based on echocardiographic examinations is shown in Table 2. One hundred fourteen (35.1\%) patients had normal examinations, 39 (12.0\%) had LV dysfunction alone, 38 (11.7\%) had RV dysfunction alone, $76(23.4 \%)$ had diastolic dysfunction alone, and $58(17.8 \%)$ had a combination of LV, RV and diastolic dysfunction. Mild LV dysfunction was statistically more common in survivors compared to non-survivors and LVEF was statistically higher among the nonsurvivors, although the median value was the same for both groups. Hospital mortality was $53.5 \%$ for patients with normal echocardiographic examinations and 35.9\% for those with isolated LV dysfunction ( $P=0.058$ compared to normal), $60.5 \%$ for those with isolated RV dysfunction $(P=0.451$ compared to normal), $48.7 \%$ for those with isolated diastolic dysfunction $(P=0.514 \mathrm{com}$ pared to normal), and $48.3 \%$ for those with a combination of LV, RV and diastolic dysfunction $(P=0.516$ compared to normal). Cumulative fluid balance was similar at 24 hours and 8 days following the onset of septic shock for patients with and without cardiac dysfunction (Figure 3).

\section{Outcomes and multivariate analysis}

ICU and hospital lengths of stay were significantly greater among non-survivors compared to survivors (ICU; 5.8 days (2.8 days, 11.6 days) vs. 4.4 days (2.0 days, 8.8 days), $P=0.016$ ) (Hospital; 14.5 days (8.7 days, 27.8 days) vs. 7.3 days (3.4 days, 15.0 days), $P<0.001$ ). Multivariate analysis identified increasing APACHE II scores, age, LVEF and the greatest quartile of positive net fluid balance at eight days post-shock onset as independent risk factors for hospital mortality (Table 3). Similarly, the propensity score analysis found the greatest quartile of positive net fluid balance at eight days post-shock onset (Quartile 4) to be significantly associated with greater mortality (adjusted odds ratio $(\mathrm{AOR})=$ $1.34 ; 95 \% \mathrm{CI}=1.19$ to $1.50 ; P=0.013)$.

\section{Discussion}

Our study demonstrated that daily and overall cumulative fluid balance predicts outcome in patients with septic shock. We also found a dose-response relationship between 24-hour and 8-day net fluid balance quartiles and hospital mortality. The greatest quartile of positive 


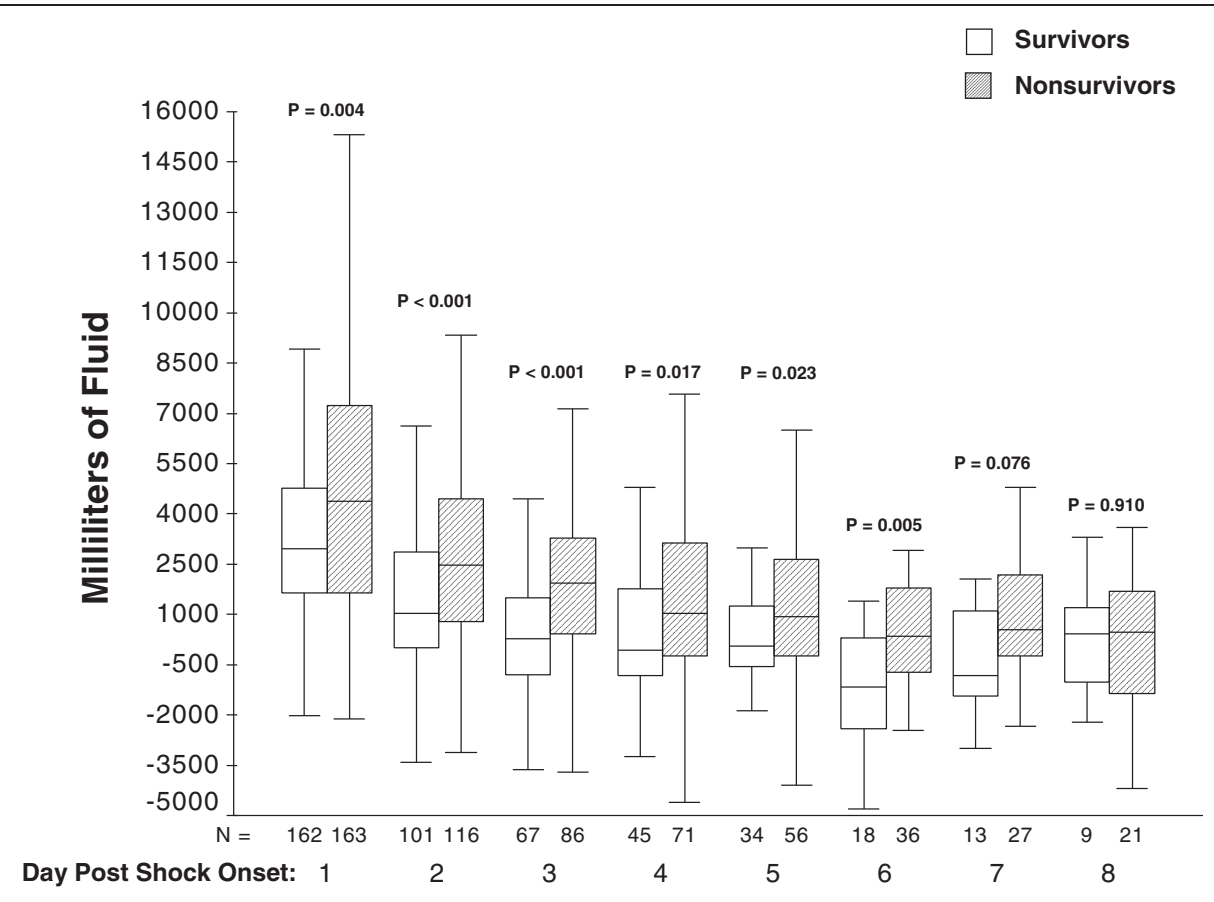

Figure 1 Box plots depicting daily cumulative fluid balance for survivors (white boxes) and non-surviviors (hatched boxes). The lines within the boxes represented the $50^{\text {th }}$ percentile, the lines at the bottom and top of the boxes represent the $25^{\text {th }}$ and $75^{\text {th }}$ percentiles, and the whisker lines represent the $5^{\text {th }}$ and $95^{\text {th }}$ percentiles.

net fluid balance at eight days post-shock onset was also found to have the greatest adjusted odds ratio associated with hospital mortality in our multivariate analysis. LVEF was also a predictor of outcome.

Our results are consistent with those of Boyd et al. who showed that more positive fluid balance both early in resuscitation and cumulatively over four days was associated with an increased risk of mortality in septic shock [10]. These findings are consistent in showing that early and late net fluid balance assessed as quartiles of fluid balance predict hospital mortality. The daily differences in fluid balance from our study also correlated with outcome through Day 6, similar to our earlier study of septic shock complicated by ALI [9]. Boyd et al. also found that CVP predicted mortality at 12 hours following septic shock but not thereafter [10]. We did not find any independent predictive value in the CVP values obtained within the 24-hour window following septic shock onset, although a modest correlation between CVP and cumulative fluid balance in the first 24 hours was observed.

Other investigators have found associations between fluid balance and outcome in septic patients. Cordemans et al. observed that fluid balance and extravascular lung water index were predictors of mortality in critically ill patients requiring mechanical ventilation [11]. Maitland et al. studied children with severe febrile illness and impaired perfusion in resource-limited African countries who received either intravenous fluid boluses $(20$ to $40 \mathrm{mg} / \mathrm{kg}$ of body weight) or no fluid bolus [23]. Fluid bolus administration was associated with significantly increased 48-hour and 4-week mortality. A recent investigation evaluating critically ill cancer patients, many of whom had underlying infections, also found that positive fluid balance was independently associated with mortality [24].

The mechanisms by which positive fluid balance can adversely influence outcomes are not known. However, prolonging time on mechanical ventilation, due to positive fluid balance and increased lung water, could contribute to the development of nosocomial infections and other adverse outcomes $[8,25,26]$. The interruption of geneticallydetermined catecholamine-mediated host defense responses by the rapid increase in plasma volume might result in a reperfusion injury [27]. Additionally, hypervolemia or hyperosmolarity might exacerbate capillary leaks in patients with septic shock contributing to intracranial hypertension or pulmonary edema [28]. Positive fluid balance could also result in intra-abdominal hypertension contributing to the development of organ hypoperfusion and subsequent organ failure [5,29].

We also observed that more normal LV function and slightly greater LVEF were associated with a greater risk of mortality. These results are consistent with those of other investigators who showed that LV systolic dysfunction was associated with improved 28-day all-cause mortality in sepsis [12,30]. Many hypotheses have been proposed for 

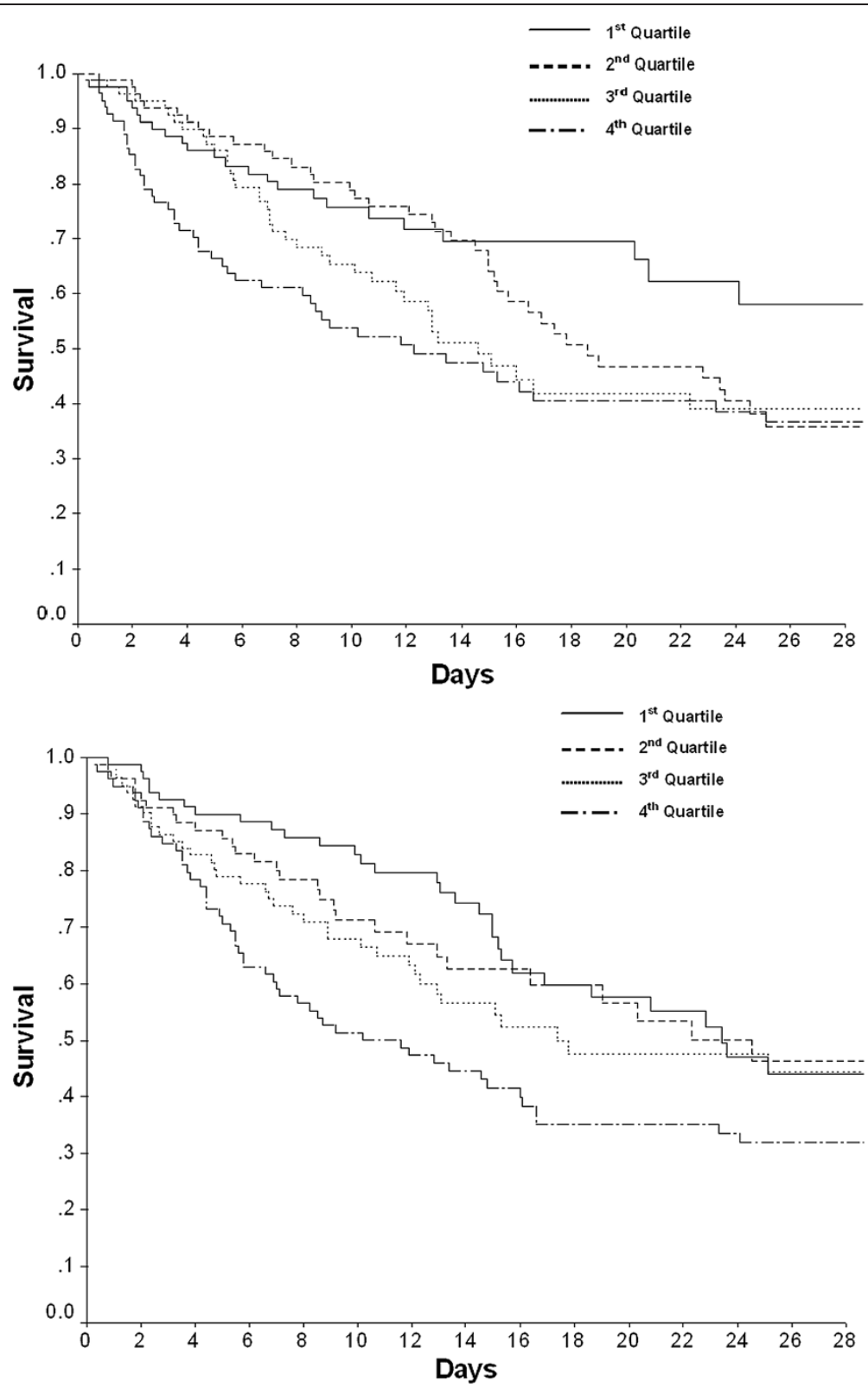

Figure 2 Cox survival curves, adjusted for age, APACHE II scores, and the use of vasopressin are shown for fluid balance quartiles, 24 hours (Top) and at Day 8 (Bottom). Quartile 4 has significantly decreased survival risk compared to quartiles 1 and 2 at 24 hours and 8 days, respectively.

myocardial depression in septic shock. However, most of them could not explain why survivors exhibited more marked myocardial depression $[12,30]$. Levy et al. documented myocardial hibernation to be present in sepsis by using magnetic resonance imaging, positron emission tomography and single-photon emission computed tomography imaging [31]. Myocardial hibernation is an adaptive response to maintain myocardial viability for prevention of cell-death pathway activation and preserves cardiac myocytes by down-regulation of oxygen consumption and energy requirements. Persistent vasoplegia is an- other potential explanation for our findings. The same level of LVEF may correspond to very different levels of intrinsic LV contractility [32]. For instance, normal values for LVEF may correspond to more severely impaired LV contractility in the presence of decreased vascular tone. This is supported by our observation that non-survivors required more vasopressors for a longer period of time, yet had slightly greater values for LVEF. The presence of a hyperkinetic state during sepsis associated with persistent and profound vasoplegia could represent the presence of uncontrolled infection and sustained inflammation [12]. 

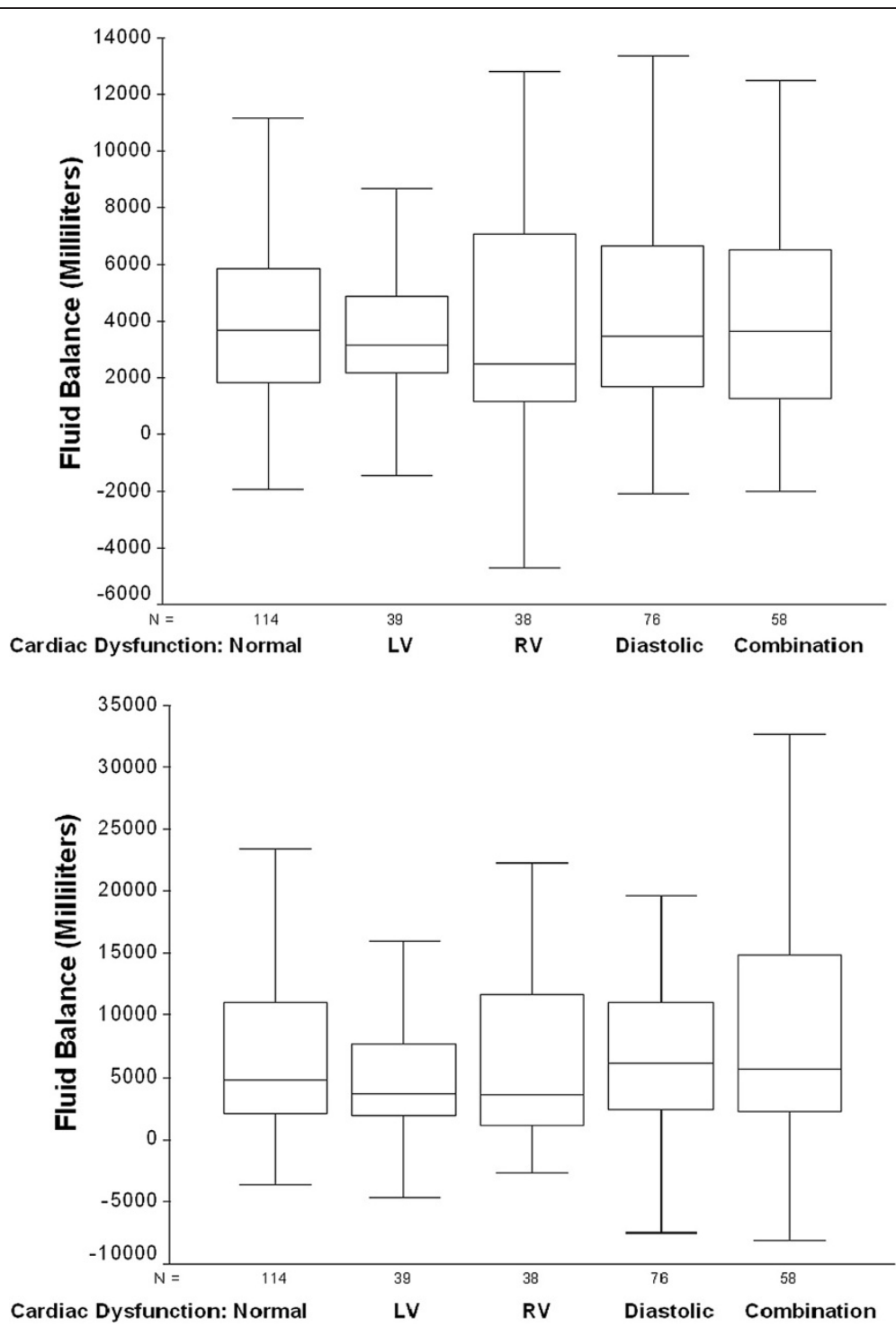

Figure 3 Box plots depicting cumulative fluid balance at 24 hours (Top) and 8 days (Bottom) following shock onset for patients with and without cardiac dysfunction demonstrated by echocardiographic examinations. LV, left ventricle; RV, right ventricle.

Our study has several important limitations. First, it was performed in a large teaching hospital and may not be generalizable to other types of institutions. However, the results are consistent with those demonstrated by other investigations suggesting that these findings are more generalizable [9-11,23-26,33]. Second, the retrospective study design limits our ability to determine a causal relationship between fluid management and the outcomes we evaluated. Third, a formal protocol for fluid management of septic shock was present but

Table 3 Multivariate analysis of independent risk factors for hospital mortality*

\begin{tabular}{|c|c|c|c|}
\hline & Adjusted odds ratio & $95 \% \mathrm{Cl}$ & $\mathbf{P}$ \\
\hline APACHE II score (one-point increments) & 1.05 & 1.03 to 1.07 & 0.035 \\
\hline Age (one-year increments) & 1.02 & 1.01 to 1.03 & 0.028 \\
\hline Left ventricle ejection fraction (one-point increments) & 1.04 & 1.02 to 1.06 & 0.025 \\
\hline Greatest quartile of positive net fluid balance at eight days post-shock onset (quartile 4) & 1.66 & 1.39 to 1.98 & 0.004 \\
\hline
\end{tabular}

*Other covariates not in the table had a $P$-value $>0.05$ including use of dobutamine, vasopressin or epinephrine; presence of abnormal left ventricle function; presence of abnormal right ventricle function; diastolic dysfunction; 24-hour cumulative fluid balance quartiles; and inappropriate antibiotic therapy (HosmerLemeshow goodness-of-fit test, $P=0.422$ ). APACHE, Acute Physiology and Chronic Health Evaluation. 
limited to the initial administration of a fluid bolus of $20 \mathrm{ml} / \mathrm{kg}$, with subsequent fluid therapy provided by goal-directed parameters $[17,18]$. The validity of this approach awaits the results of ongoing prospective trials. Fourth, we did not routinely utilize direct or indirect measures of stroke volume to guide our fluid therapy. Finally, despite achieving AIFR and appropriate antibiotic therapy in the majority of our patients, we cannot be certain that some other unmeasured clinical parameter or process of care variable may have contributed to our findings.

\section{Conclusions}

The fluid management and cardiac function of patients with septic shock appear to be important potentially modifiable determinants of hospital mortality. These data support the need for prospective trials aimed at identifying the optimal strategies for hemodynamic management of septic shock to include fluid administration and cardiac support measures.

\section{Key messages}

- Cumulative fluid balance and cardiac function predict outcome in patients with septic shock.

- Clinicians treating patients with septic shock should carefully assess the need for intravenous fluids both in the immediate resuscitation period and over the subsequent days of treatment.

- The use of more conservative fluid administration protocols in patients with severe sepsis and septic shock needs additional study to determine their relative efficacy compared to standard of care therapy.

\section{Abbreviations}

AIFR: Adequate initial fluid resuscitation; ALl: Acute lung injury; AOR: Adjusted odds ratio; APACHE: Acute physiology and chronic health Evaluation; Cl: Confidence interval; CVP: Central venous pressure; ICU: Intensive care unit; IQR: Interquartile range; LV: Left ventricle; LVEF: Left ventricular ejection fraction; RV: Right ventricle; $\mathrm{S}_{\mathrm{CV}} \mathrm{O}_{2}$ : Central venous oxygen saturation; SD: Standard deviation; TDI: Tissue Doppler imaging.

\section{Competing interests}

Dr. Kollef's effort was supported by the Barnes-Jewish Hospital Foundation. The authors have no conflicts of interest to report in relation to this manuscript.

\section{Authors' contributions}

MHK, CM, MM, NH, JAD and STM had full access to all of the data in the study and take responsibility for the integrity of the data and the accuracy of the data analysis. MHK and CM contributed to the study conception and design, statistical analysis, drafting of the manuscript, and have given approval to the final version. MM and $\mathrm{NH}$ contributed to the study conception and design, statistical analysis, and have given approval to the final version. JAD contributed to the study conception and database construction, and drafting of the manuscript and has given approval to the final version. STM contributed to the study conception and design, statistical analysis, and drafting of the manuscript and has given approval to the final version. All authors read and approved the final manuscript.

\section{Acknowledgment}

We thank Rebecca Light for outstanding efforts in the administrative support of this study and manuscript preparation.

\section{Author details}

${ }^{1}$ St. Louis College of Pharmacy, 4588 Parkview Place, St. Louis, MO 63110, USA. ${ }^{2}$ Division of Pulmonary and Critical Care Medicine, Washington University School of Medicine, 660 South Euclid Avenue, Campus Box 8052, St. Louis, MO 63110, USA. ${ }^{3}$ BJC Center for Clinical Excellence, 4901 Forest Park Avenue, St. Louis, MO 63108, USA. ${ }^{4}$ Medical Informatics, BJC Learning Institute, 8300 Eager Road, St. Louis, MO 63144, USA.

Received: 19 June 2013 Accepted: 23 September 2013

Published: 20 October 2013

\section{References}

1. Dellinger RP, Levy MM, Carlet JM, Bion J, Parker MM, Jaeschke R, Reinhart K, Angus DC, Brun-Buisson C, Beale R, Calandra T, Dhainaut JF, Gerlach H, Harvey M, Marini JJ, Marshall J, Ranieri M, Ramsay G, Sevransky J, Thompson BT, Townsend S, Vender JS, Zimmerman JL, Vincent JL, International Surviving Sepsis Campaign Guidelines Committee, American Association of Critical-Care Nurses, American College of Chest Physicians, American College of Emergency Physicians, Canadian Critical Care Society, European Society of Clinical Microbiology and Infectious Diseases, et al: Surviving sepsis campaign: international guidelines for management of severe sepsis and septic shock: 2008. Crit Care Med 2008, 36:296-327.

2. Rivers E, Nguyen B, Havstad S, Ressler J, Muzzin A, Knoblich B, Peterson E, Tomlanovich M, Early Goal-Directed Therapy Collaborative Group: Early goal-directed therapy in the treatment of severe sepsis and septic shock. N Engl J Med 2001, 345:1368-1377.

3. Guillamet MC, Rhee C, Patterson AJ: Cardiovascular management of septic shock in 2012. Curr Infect Dis Rep 2012, 14:493-502.

4. Dellinger RP, Levy MM, Rhodes A, Annane D, Gerlach H, Opal SM, Sevransky JE, Sprung CL, Douglas IS, Jaeschke R, Osborn TM, Nunnally ME, Townsend SR, Reinhart K, Kleinpell RM, Angus DC, Deutschman CS, Machado FR, Rubenfeld GD, Webb SA, Beale RJ, Vincent JL, Moreno R, Surviving Sepsis Campaign Guidelines Committee including the Pediatric Subgroup: Surviving sepsis campaign: international guidelines for management of severe sepsis and septic shock: 2012. Crit Care Med 2013, 41:580-637.

5. Balogh Z, Moore FA, Moore EE, Biffl WL: Secondary abdominal compartment syndrome: a potential threat for all trauma clinicians. Injury 2007, 38:272-279.

6. Coats TJ, Brazil E, Heron M, MacCallum PK: Impairment of coagulation by commonly used resuscitation fluids in human volunteers. Emerg Med J 2006, 23:846-849.

7. Krausz MM: Initial resuscitation of hemorrhagic shock. World J Emerg Surg 2006, 1:14.

8. National Heart Lung, and Blood Institute Acute Respiratory Distress Syndrome (ARDS) Clinical Trials Network, Wiedemann HP, Wheeler AP, Bernard GR, Thompson BT, Hayden D, de Boisblanc B, Connors AF Jr, Hite $\mathrm{RD}$, Harabin AL: Comparison of two fluid-management strategies in acute lung injury. N Engl I Med 2006, 354:2564-2575.

9. Murphy CV, Schramm GE, Doherty JA, Reichley RM, Gajic O, Afessa B, Micek ST, Kollef $\mathrm{MH}$ : The importance of fluid management in acute lung injury secondary to septic shock. Chest 2009, 136:102-109.

10. Boyd JH, Forbes J, Nakada TA, Walley KR, Russell JA: Fluid resuscitation in septic shock: a positive fluid balance and elevated central venous pressure are associated with increased mortality. Crit Care Med 2011, 39:259-265.

11. Cordemans C, De Laet I, Van Regenmortel N, Schoonheydt K, Dits H, Huber W, Malbrain ML: Fluid management in critically ill patients: the role of extravascular lung water, abdominal hypertension, capillary leak, and fluid balance. Ann Intensive Care 2012, 2:S1.

12. Weng L, Liu YT, Du B, Zhou JF, Guo XX, Peng JM, Hu XY, Zhang SY, Fang Q, Zhu WL: The prognostic value of left ventricular systolic function measured by tissue Doppler imaging in septic shock. Crit Care 2012, 16:R71.

13. Landesberg G, Gilon D, Meroz Y, Georgieva M, Levin PD, Goodman S, Avidan A, Beeri R, Weissman C, Jaffe AS, Sprung CL: Diastolic dysfunction and mortality in severe sepsis and septic shock. Eur Heart J 2012, 33:895-903. 
14. Pulido JN, Afessa B, Masaki M, Yuasa T, Gillespie S, Herasevich V, Brown DR, Oh JK: Clinical spectrum, frequency, and significance of myocardial dysfunction in severe sepsis and septic shock. Mayo Clin Proc 2012, 87:620-628.

15. Angus DC, Linde-Zwirble WT, Lidicker J, Clermont G, Carcillo J, Pinsky MR: Epidemiology of severe sepsis in the United States: analysis of incidence, outcome, and associated costs of care. Crit Care Med 2001, 29:1303-1310.

16. Knaus WA, Draper EA, Wagner DP, Zimmerman JE: APACHE II: a severity of disease classification system. Crit Care Med 1985, 13:818-829.

17. Micek ST, Roubinian N, Heuring T, Bode M, Williams J, Harrison C, Murphy T, Prentice D, Ruoff BE, Kollef MH: Before-after study of a standardized hospital order set for the management of septic shock. Crit Care Med 2006, 34:2707-2713.

18. Thiel SW, Asghar MF, Micek ST, Reichley RM, Doherty JA, Kollef MH: Hospital-wide impact of a standardized order set for the management of bacteremic severe sepsis. Crit Care Med 2009, 37:819-824.

19. Kollef MH, Napolitano LM, Solomkin JS, Wunderink RG, Bae IG, Fowler VG, Balk RA, Stevens DL, Rahal JJ, Shorr AF, Linden PK, Micek ST: Health care-associated infection (HAl): a critical appraisal of the emerging threat-proceedings of the HAI Summit. Clin Infect Dis 2008, 47:S55-S99.

20. Schiller NB, Shah PM, Crawford M, DeMaria A, Devereux R, Feigenbaum H, Gutgesell H, Reichek N, Sahn D, Schnittger I: Recommendations for quantitation of the left ventricle by two-dimensional echocardiography. American Society of Echocardiography Committee on Standards, Subcommittee on Quantitation of Two-Dimensional Echocardiograms. J Am Soc Echocardiogr 1989, 2:358-367.

21. Nagueh SF, Appleton CP, Gillebert TC, Marino PN, Oh JK, Smiseth OA, Waggoner AD, Flachskampf FA, Pellikka PA, Evangelisa A: Recommendations for the evaluation of left ventricular diastolic function by echocardiography. Eur J Echocardiogr 2009, 10:165-193.

22. Wahl A, Praz F, Schwerzmann M, Bonel H, Koestner SC, Hullin R, Schmid JP, Stuber T, Delacrétaz E, Hess OM, Meier B, Seiler C: Assessment of right ventricular systolic function: comparison between cardiac magnetic resonance derived ejection fraction and pulsed-wave tissue Doppler imaging of the tricuspid annulus. Int J Cardio/ 2011, 151:58-62.

23. Maitland K, Kiguli S, Opoka RO, Engoru C, Olupot-Olupot P, Akech SO, Nyeko R, Mtove G, Reyburn H, Lang T, Brent B, Evans JA, Tibenderana JK, Crawley J, Russell EC, Levin M, Babiker AG, Gibb DM, FEAST Trial Group: Mortality after fluid bolus in African children with severe infection. N Engl J Med 2011, 364:2483-2495.

24. de Almeida JP, Palomba H, Galas FR, Fukushima JT, Duarte FA, Nagaoka D, Torres V, Yu L, Vincent JL, Auler JO Jr, Hajjar LA: Positive fluid balance is associated with reduced survival in critically ill patients with cancer. Acta Anaesthesio/ Scand 2012, 56:712-717.

25. Mekontso Dessap A, Roche-Campo F, Kouatchet A, Tomicic V, Beduneau G, Sonneville R, Cabello B, Jaber S, Azoulay E, Castanares-Zapatero D, Devaquet J, Lellouche F, Katsahian S, Brochard L: Natriuretic peptide-driven fluid management during ventilator weaning. A randomized controlled trial. Am J Respir Crit Care Med 2012, 186:1256-1263.

26. Trof RJ, Beishuizen A, Cornet AD, de Wit RJ, Girbes AR, Groeneveld AB: Volume-limited versus pressure-limited hemodynamic management in septic and nonseptic shock. Crit Care Med 2012, 40:1177-1185.

27. Myburgh JA: Fluid resuscitation in acute illness - time to reappraise the basics. N Engl J Med 2011, 364:2543-2544.

28. The SAFE Study Investigators: Saline or albumin for fluid resuscitation in patients with traumatic brain injury. N Engl J Med 2007, 357:874-884.

29. Ke L, Ni HB, Sun JK, Tong ZH, Li WQ, Li N, Li JS: Risk factors and outcome of intra-abdominal hypertension in patients with severe acute pancreatitis. World J Surg 2012, 36:171-178.

30. Weng L, Liu Y, Zhou J, Guo X, Peng J, Hu X, Fang Q, Zhu W, Li H, Du B, Zhang S: Left ventricular systolic function and systolic asynchrony in patients with septic shock and normal left ventricular ejection fraction. Shock 2013, 40:175-181.
31. Levy RJ, Piel DA, Acton PD, Zhou R, Ferrari VA, Karp JS, Deutschman CS: Evidence of myocardial hibernation in the septic heart. Crit Care Med 2005, 33:2752-2756.

32. Robotham JL, Takata M, Berman M, Harasawa Y: Ejection fraction revisited. Anesthesiology 1991, 74:172-183.

33. Payen D, de Pont AC, Sakr Y, Spies C, Reinhart $K$, Vincent JL: A positive fluid balance is associated with a worse outcome in patients with acute renal failure. Crit Care 2008, 12:R74

doi:10.1186/cc13072

Cite this article as: Micek et al:: Fluid balance and cardiac function in septic shock as predictors of hospital mortality. Critical Care 2013 17:R246.

\section{Submit your next manuscript to BioMed Central and take full advantage of:}

- Convenient online submission

- Thorough peer review

- No space constraints or color figure charges

- Immediate publication on acceptance

- Inclusion in PubMed, CAS, Scopus and Google Scholar

- Research which is freely available for redistribution

Submit your manuscript at www.biomedcentral.com/submit
C) BioMed Central 